Notas e Informações/Notes and Information

\title{
NOTA SOBRE ENCONTRO DE PHLEBOTOMINAE (DIPTERA: PSYCHODIDAE) NO LITORAL SUL DO ESTADO DE SÃO PAULO, BRASIL.*
}

\author{
Almério de Castro Gomes** \\ Eunice Aparecida Bianchi Galati** \\ Carmen Moreno Classer ${ }^{* * *}$
}

\begin{abstract}
GOMES, A. de C. et al. Nota sobre encontro de Phlebotominae (Diptera: Psychodidae) no litoral sul do Estado de São Paulo, Brasil. Rev. Saúde públ., S. Paulo, 24: 319-20, 1990.

RESUMO: Durante as realizaçōes de dois estudos sobre mosquito Culicidae, empregando-se armadilhas luminosas tipo CDC e Shanon, além de isca humana, foram capturados cinco espécies de Phlebotominae, entre as quais se encontravam Lutzomyia intermedia e L. flaviscutellata. As localidades investigadas eram alagadiças e raros casos humanos de leishmaniose tegumentar foram registrados entre os moradores locais. As duas situações sugerem ser estes casos autóctones.
\end{abstract}

DESCRITORES: Psychodidae. Leishmaniose mucocutânea, epidemiologia. Ecologia de vetores.

A baixada litorânea situada ao sul do Estado de São Paulo possui condições mesológicas gerais representadas visivelmente por terreno facilmente inundável durante as estaçōes chuvosas e ainda potencializado pelos efeitos da maré alta. A vegetação florestal é composta pela restinga e mata quaternária (Forattini e col, 1986). Por este motivo nunca houve interesse para estudos de Phlebotominae nesta faixa geográfica. Todavia, a coleta de alguns representantes desta subfamília, quando da investigação sobre o mosquito Culicidae na região, merece consideraçōes sobre seu significado epide-miológico.

Como foi mencionado, as coletas de flebotomíneos ocorreram conjuntamente às de culicídeos, com emprego de isca humana, armadilha luminosa tipo CDC e armadilha de Shannon. Os pontos de coletas foram distribuídos desde o interior da mata até o peridomicílio das raras habitações humanas ali existentes, e corresponderam às localidades como o sítio Vilarinho e Folha Larga, no Município de Cananéia e sítio Palmeira no Município de Iguape. $O$ período da pesquisa para as duas primeiras localidades foi de janeiro/1983 a fevereiro/1984, enquanto que para a última foi de janeiro/1988 a março/1989.

Durante doze ou treze meses ininterruptos de co- letas de culicídeos, várias espécies de flebotomíneos foram acidentalmente sendo assinaladas nas armadilhas, principalmente na CDC. No sítio Vilarinho tivemos Psychodopygus ayrozai (82 $Q \bigcirc$ e $\left.830^{\circ} 0^{\circ}\right)$; Lutzomyia flaviscutellata (1 ९) e Lutzomyia guyanensis (1 ९). Em Folha Larga, P. ayrozai (57 ९९ $\left.66 \sigma^{\circ} \sigma^{\circ}\right)$; Lutzomyia intermedia (2 ९९); L. flaviscutellata ( 1 ) e Lutzomyia lanei (1 $\left.)^{\circ}\right)$. No sítio Palmeira foi capturado apenas $L$. intermedia (26 ९९ e 9 ९९).

Face aos resultados de 329 flebotomíneos capturados, ampliam-se os conhecimentos sobre a distribuição espacial do grupo na região do Vale do Ribeira, Estado de São Paulo, sendo que duas espécies presentes estão envolvidas como vetoras de Leishmania. Não obstante ao reduzido número de exemplares obtidos, este achado se reveste de significado epidemiológico porque evidencia condição potencial para ocorrência de casos humanos autóctones de leishmaniose tegumentar nos dois municípios. Alías, no período de 1980 até abril de 1990 foi, nesses municípios, notificada a doença em indivíduos cujos locais de residência corresponderam às localidades de Guaxixi de dentro (1); Carijo (1); Rio das Minas (1) e Cortão do Andrade (1), totalizando 5 casos no Município de Cananéia. Já o total de 7 casos de Iguape estão assim distribuídos: bairro Rocio (3); Samambi I (1); Tucunduva II (1);

\footnotetext{
* Pesquisa em andamento sobre Culicidae, financiada pela FINEP (Processo $n^{\circ} B / 76 / 80 / 238 / 00 / 00$ ) e FAPESP ( ${ }^{\circ}$ 88/1159-0).

* Departamento de Epidemiologia da Faculdade de Saúde Pública da Universidade de São Paulo - Av. Dr. Arnaldo, 715 - 01255 - São Paulo, SP - Brasil.

** Superintendência de Controle de Endemias (SUCEN), Regional de Registro - Av. Dr. Waldemar L. Ferraz, 516 - 11900 -Registro, SP - Brasil.
} 
Momuna (1) e Arataca (1). Estas informações revelam aspecto disperso e esporádico dos casos de infecção humana, decorrentes possivelmente da existência de uma baixa exposição do homem à picada de flebotomíneo, fato já discutido por Gomes e Galati ${ }^{2}$ (1989). Ressalte-se ainda que as investigações feitas anteriormente sugeriram ser o local de infecção o mesmo da residência, aspecto este reforçado pela presença de $L$. intermedia em ambiente alterado do sítio Palmeira. As infecções humanas registradas no bairro Rocio da cidade de Iguape sugerem relação com outros focos que têm esta espé- cie como vetora. Sobre $L$. flaviscutellata, do ambiente florestado e portador de hábito zoofílico, não se tem evidência sobre seu papel vetorial local; contudo, se os casos referidos aqui ocorreram predominantemente em indivíduos que residem próximos a mata primária, não se poderá também excluí-lo de uma eventual responsabilidade.

Com este conhecimento adicional ampliam-se as áres potenciais e ecologicamente distintas para a ocorrência da transmissão de leishmaniose tegumentar na região do Vale do Ribeira.

GOMES, A. de C. et al. [Note on the finding of Phlebotominae (Diptera: Psychodidae) on the Southern part of the coast of State of S. Paulo, Brazill. Rev. Saúde públ., S. Paulo, 24: 319-20, 1990.

ABSTRACT: Five species of phlebotomine sandflies were cought on the Southern part of the coast of S. Paulo, Brazil. CDC-light and Shannon traps were used, as well as human-bait, during two investigations into Culicidae moquitoes. Lutzomyia intermedia and L. flaviscutellata were found among those sandflies. The locaties investigated were swampy environments and scant human cases of cutaneous leishmaniasis have been notified there. Both situations suggest the autoch thonous nature of the human cases registered there.

KEYWORDS: Psychodidae. Leishmaniasis, mucocutaneous, epidemiology. Ecology, vectors.

\section{REFERÊNCIAS BIBLIOGRÁFICAS}

1. FORATTINI, O. P.; GOMES, A. de C.; NATAL, D. SANTOS, J. L. F. Observaçōes sobre atividade do mosquito Culicidae em matas primitivas da planície e perfis epidemiológicos de vários ambientes no Vale do Ribeira, São Paulo, Brasil. Rev. Saúde públ., S. Paulo, 20:178-203, 1986.

2. GOMES, A. de C. \& GALATI, E. A. B. Aspectos ecológicos da leishmaniose tegumentar americana.
7. Capacidade vetorial flebotomínea em ambiente florestal primário do Sistema da Serra do Mar, região do Vale do Ribeira, Estado de São Paulo, Brasil. Rev. Saúde públ., S. Paulo, 23: 136-42, 1989.

Recebido para publicação em 5/6/1990. Aprovado para publicação em 11/6/90. 